\title{
Prevalence of tick infestation in dogs in and around Bhubaneswar
}

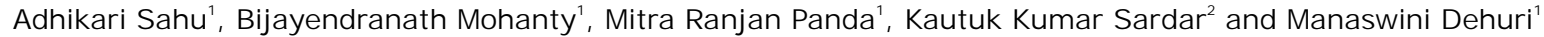

1. Department of Veterinary Parasitology, College of Veterinary Science \& Animal Husbandry, Orissa University of Agriculture \& Technology, Bhubaneswar-751 003, Odisha, India; 2. Department of Veterinary Pharmacology \& Toxicology, College of Veterinary Science \& Animal Husbandry, Orissa University of Agriculture \& Technology, Bhubaneswar-751 003, Odisha, India

Corresponding author: Bijayendranath Mohanty, email: bijayendranath@gmail.com

Received: 13-10-2013, Revised: 04-11-2013, Accepted: 05-11-2013, Published online: 13-12-2013

doi: $10.14202 /$ vetworld.2013.982-985

How to cite this article: Sahu A, Mohanty B, Panda MR, Sardar KK and Dehuri M (2013) Prevalence of tick infestation in dogs in and around Bhubaneswar, Veterinary World 6(12): 982-985.

\begin{abstract}
Aim: To study the prevalence of tick infestation in dogs in and around Bhubaneswar.

Materials and Methods: A total of $610 \mathrm{dogs}$ (360 stray dogs \& 250 pet dogs) in and around Bhubaneswar belonging to either sex were examined for tick infestation during a period of one year (Aug 2011- July 2012). Standard parasitological procedures were followed for collection, processing and identification of ticks.

Result: 283 dogs (46.39\%) were found positive for tick infestation with three different ixodid tick spp., viz. Rhipicephalus spp (39.51\%), Boophilus spp.(4.92\%) and Haemaphysalis spp. (1.97\%) with many dogs having mixed infestations. Higher rate of incidence was recorded among stray dogs (58.33\%) as compared to pet dogs (29.20\%). Prevalence among dogs less than 1 year of age was higher $(53.41 \%)$ than dogs above one year $(45.21 \%)$. The overall percentage of incidence was higher $(53.97 \%)$ among males than females $(38.31 \%)$ in both stray and pet dogs. Influence of age and the variation due to sex on prevalence of tick infestations was found to be statistically significant $(\mathrm{p}<0.05)$. Highest percentage of prevalence $(48.86 \%)$ was recorded during rainy season followed by summer season $(40.39 \%)$ and lowest $(32.24 \%)$ in winter. Influence of season on the prevalence of tick infestation was highly significant $(\mathrm{p}<0.01)$.
\end{abstract}

Conclusion: Our study revealed the occurrence of three types of ixodid ticks in dogs with a prevalence of mixed infestation. Influence of age, sex and season on the prevalence of tick infestation was found to be significant.

Key words: Boophilus, Haemaphysalis, prevalence, Rhipicephalus, ticks.

\section{I ntroduction}

Ticks, like other arthropods, live as blood sucking ectoparasites. These are the most important group of arthropods which act as vectors of many bacterial, viral, rickettsial and protozoan diseases of dogs. Ticks attach to the dog's body, suck blood causing anemia and can transmit diseases like ehrlichiosis, anaplasmosis, babesiosis, hepatozoonosis, bartenellosis, lyme disease and some zoonotic diseases like Rocky mountain spotted fever and Tularemia. Tick bite causes irritation, redness, swelling, itching and self trauma. One of the most harmful impacts of tick bite is the release of neurotoxins from tick saliva leading to tick paralysis, systemic illness and hypersensitivity reactions [1]. In general, different parasitic infestations including tick infestations are more prevalent in stray dogs, but the pet dogs which directly or indirectly get exposed to stray dogs also frequently suffer from different parasitic infestations.

Climatic conditions in India are quite favourable for growth and multiplication of arthropods [2]. Among different species of ticks infesting dogs, Rhipicephalus sanguineus (brown dog tick) is most

Copyright: The authors. This article is an open access article licensed under the terms of the Creative Commons Attribution License (http://creativecommons.org/licenses/by/2.0) which permits unrestricted use, distribution and reproduction in any medium, provided the work is properly cited. commonly present [3-8]. Besides this, other Ixodid ticks infesting dogs belong to different genera viz. Haemaphysalis, Ixodes, Boophilus, Dermacenter and Amblyoma which occur with varied level of prevalence in different parts of world [9-14]. Otobius megnini is the only soft tick species found in dogs [15].

Different control strategies against ticks and tick borne diseases like integrated pest management (IPM) have been adopted to reduce the intensity of acaricide use; measures that can minimize the chance of drug resistance, using new generation herbal acaricides, development of tick vaccines and biological control methods. Though it was applied for cattle in Australia, Latin America and Africa [16,17], no such program has been implemented yet for control of ticks in dogs.

Because these ticks infesting dogs can come in contact with human beings or other animals while in close proximity and cause serious zoonotic diseases, the present study was conducted to assess the prevalence of tick infestation among pet and stray dogs with an aim to develop a strategic control programme against tick infestations in dogs in and around Bhubaneswar.

\section{Materials and Methods}

Ethical approval: The experiment was done in accordance with the guidelines provided by the institutional ethical committee and also complies with the country's laws. 
Table-1. Species/Age/Sex/Season Wise Prevalence of Tick Infestation in Dogs

\begin{tabular}{|c|c|c|c|c|c|c|c|c|c|c|}
\hline \multirow[t]{2}{*}{ Prevalence } & \multirow[t]{2}{*}{ Particulars } & \multicolumn{3}{|c|}{ Pet Dogs } & \multicolumn{3}{|c|}{ Stray Dogs } & \multicolumn{3}{|c|}{ Total } \\
\hline & & $\mathbf{E}$ & $\mathbf{P}$ & $\%$ & $\mathbf{E}$ & $\mathbf{P}$ & $\%$ & $\mathbf{E}$ & $\mathbf{P}$ & $\%$ \\
\hline \multirow[t]{5}{*}{ Species wise } & Rhipicephalus & 250 & 58 & 23.20 & 360 & 183 & 50.83 & 610 & 241 & 39.51 \\
\hline & Boophilus & 250 & 12 & 4.80 & 360 & 18 & 5.00 & 610 & 30 & 4.92 \\
\hline & Haemaphysalis & 250 & 3 & 1.20 & 360 & 9 & 2.50 & 610 & 12 & 1.97 \\
\hline & Total & 250 & 73 & 29.20 & 360 & 210 & 58.33 & 610 & 283 & 46.39 \\
\hline & $x^{2}$ & 79.24 ** & 340.38 ** & $406.65^{* *}$ & & & & & & \\
\hline \multirow[t]{4}{*}{ Age wise } & $<1$ Year & 58 & 21 & 36.21 & 30 & 26 & 86.67 & 88 & 47 & 53.41 \\
\hline & $>1$ year & 192 & 52 & 27.08 & 330 & 184 & 55.76 & 522 & 236 & 45.21 \\
\hline & Total & 250 & 73 & 29.20 & 360 & 210 & 58.33 & 610 & 283 & 46.39 \\
\hline & $\chi^{2}$ & $1.79^{\mathrm{NS}}$ & $10.80^{* *}$ & $2.03^{N S}$ & & & & & & \\
\hline \multirow[t]{4}{*}{ Sex Wise } & Male & 145 & 48 & 33.10 & 170 & 122 & 71.76 & 315 & 170 & 53.97 \\
\hline & Female & 105 & 25 & 23.81 & 190 & 88 & 46.32 & 295 & 113 & 38.31 \\
\hline & Total & 250 & 73 & 29.20 & 360 & 210 & 58.33 & 610 & 283 & 46.39 \\
\hline & $x^{2}$ & $2.54^{\mathrm{NS}}$ & 23.90 ** & 14.40 ** & & & & & & \\
\hline \multirow[t]{4}{*}{ Season wise } & Rainy & 78 & 23 & 29.48 & 98 & 63 & 64.28 & 176 & 86 & 48.86 \\
\hline & Winter & 79 & 14 & 17.72 & 104 & 45 & 43.26 & 183 & 59 & 32.24 \\
\hline & Summer & 157 & 37 & 23.57 & 202 & 108 & 53.47 & 359 & 145 & 40.39 \\
\hline & $x^{2}$ & 9.10 ** & 13.65 ** & 22.61 ** & & & & & & \\
\hline
\end{tabular}

**: Highly Significant, $p<0.01 ; *$ : Significant, $p<0.05 ;$ NS: Non Significant, $p>0.05, \chi^{2}=$ Chi Sqaue value

Study period: The study was carried out for a period of one year from Aug 2011 to July 2012.

Study area: Both stray and pet dogs from different locations in and around Bhubaneswar were included in this study. The stray dogs brought to the Government Veterinary Dispensary, Saheed Nagar, Bhubaneswar for Animal Birth Control (ABC) programme (carried out jointly by the Fisheries and Animal Resources Development Department, Government of Odisha and Bhubaneswar Municipal Corporation under the direct supervision of the Animal Welfare Board of India and CPCSEA for controlling the population of stray dogs) and the pet dogs presented to the Teaching Veterinary Clinical Complex (TVCC) of the College of Veterinary Science and Animal Husbandry, OUAT, Bhubaneswar were selected randomly for the present study.

Population size: During a period of 1 year (Aug 2011July 2012), a total of 610 dogs (360 stray dogs and 250 pet dogs belonging to either sex and two different age groups ( below one year age and above one year age) were examined.

Collection of ticks: For collection of ticks, the stray dogs after being anaesthetized for animal birth control operation under ABC programme, and pet dogs after being properly restrained, were thoroughly examined (ear, neck, back and belly, inter-digital spaces and in between the thighs) and with the help of forceps freely moving ticks were collected. A drop of xylene or chloroform was placed over the point of attachment of ticks to the body in order to loosen and remove the firmly attached ticks. Ticks collected were transferred into properly labeled plastic containers having perforated stoppers and brought to the laboratory for further processing.

Processing and identification: Live ticks were first transferred into luke warm water in order to fix them in an extended position. Fixed ticks were preserved in glycerinated $70 \%$ alcohol. Some of the representative specimens of either sex were subjected to permanent mounting for morphological study as per the procedure described by Soulsby [18].

Statistical analysis: The data recorded during the present study were subjected to statistical analysis using Statistical Package for Social Science (SPSS) version 17.0. Chi-square test was used to establish the association. [19]

\section{Results and Discussion}

Out of total 610 dogs (250 pet dogs and 360 stray dogs) examined over a period of one year (Aug 2011July 2012), 46.39\% dogs were found to be positive for tick infestation. The percentage of prevalence in pet dogs was $29.20 \%$ whereas in stray dogs it was $58.33 \%$ (Table-1). The study on tick prevalence in India [3, 20], Nigeria [10] Lahore, Pakistan [6] revealed infestation in $45.00 \%, 55.3 \%, 52.3 \%$ and $53 \%$ dogs, respectively. Present findings were in general agreement with the above reports. The variation in the rate of incidence between stray and pet dogs recorded during the present study might be due to the better living environment of pet dogs and regular application of acaricidal agents by the conscious pet owners.

Data on age wise prevalence of tick infestation in both pet and stray dogs under study are summarized in Table-1 which reveals higher percentage $(53.41 \%)$ of prevalence among dogs less than 1year of age than dogs above one year (45.21\%). Influence of age on prevalence of tick infestations was found higher in both stray and pet dogs that are less than 1 year of age. However, the influence of age on tick infestation was statistically significant $(\mathrm{p}<0.05)$ in respect to stray dogs only. This variation might be due to the development of resistance and effective scratching activity in adult dogs than in the young age groups. The higher percentage of incidence among dogs below 1 year of age, reported from earlier studies in Maharashtra, India [8], and in Shiraz, Iran [21], corroborates with the present observation. 
Sex wise prevalence of tick infestation in dogs is shown in Table-1. The overall percentage of prevalence was found to be higher (53.97\%) among males than females $(38.31 \%)$ in both stray and pet dogs and the variation due to sex was statistically significant $(\mathrm{p}<0.05)$. Higher percentage of tick infestations in male dogs was also recorded by earlier workers $[21,22]$. Hormonal factors might be playing some role which predisposes male dogs more to tick infestations in this area. In contrast, some workers [11,23] reported higher prevalence of tick infestation among females than males whereas no sex wise differences were observed by some others [24-27].

Three seasons namely rainy (July- October), winter (November- February) and summer (MarchJune) prevails over Bhubaneswar which has variable ambient air temperature, relative humidity and average rain fall. Analysis of data on the influence of season on prevalence of tick infestation in dogs distributed over three seasons (Table-1) revealed highest percentage $(48.86 \%)$ of prevalence during rainy season followed by summer $(40.39 \%)$ and lowest $(32.24 \%)$ in winter, and influence of season on prevalence of tick infestation was highly significant $(\mathrm{p}<0.01)$. Earlier workers $[8,23]$ have recorded highest incidence rate during post-monsoon and lowest in winter, respectively. Variation in the percentage of prevalence during different season could be attributed to the fact that the breeding of ixodid ticks is highly favoured by warm and humid climate [18], which is variable with the geographical situation of a region over the same season of a year.

Different species of ticks infesting dogs detected during the present investigation were processed and identified at least up to the genus level following the keys suggested by Soulsby [18]. Percentage of prevalence of different species of ticks infesting stray and pet dogs in and around Bhubaneswar is shown in (Table-1). Analysis of data revealed that only ixodid ticks were found to be infesting both pet and stray dogs. Only three species of ixodid ticks viz. Rhipicepalus spp., Boophilus spp., Haemaphysalis spp. were recorded from the infested dogs. Among these three spp., the overall prevalence of Rhipicephalus spp. found to be highest followed by Boophilus spp. and Haemaphysalis spp. Comparatively higher percentage of prevalence of all three species of ticks was recorded among stray dogs than pet dogs. The present findings agreed with Mishra and Mohapatra [7] who also recorded highest incidence of Rhipicephalus sanguineus followed by Hamaphysalis spp. and Boophilus spp. in Bhubaneswar. Previous workers $[4,5,10,28,29]$ also reported highest incidence of Rhipicephalus spp. in dogs. The occurrence of some tick species reported earlier from dogs elsewhere [30, 31] which were not detected during our investigation might be due to the unsuitability of the climatic condition prevailing over Bhubaneswar and nearby areas for other species of ticks.

\section{Conclusions}

Ticks are the important vectors of a wider variety of pathogenic agents than any other group of arthropods. Prevalence study to identify the epidemiological status of various tick species can guide future researchers for successful implementation of tick control programmes. Basing on our results it is concluded that the prevalence of tick infestation in dogs in the study area is higher because of the hot and humid climate. Identified risk factors (age, sex and season) should enable veterinarians to prevent tick infestations in pet dogs although differences in risk of tick infestation may be related to outdoor activity of dogs in this area. Our findings will aid in designing proper measures to reduce the chance of many vector borne diseases in general and some zoonotic diseases in particular. Hence we recommend that extensive investigation should be conducted to establish the role of ticks as vectors of diseases.

\section{Authors' contributions}

AS and BM designed the study. AS collected the samples and analysed them. BM and MRP provided technical guidance and participated in scientific investigations and discussion. KKS participated in data analysis and discussion. MD participated in the discussion and drafted the manuscript. All authors read and approved the final manuscript.

\section{Acknowledgements}

The authors acknowledge the co-operation extended by the In-charge of Animal Birth Control Program, Saheed Nagar, Bhubaneswar for collection of samples and the Dean, C.V.Sc. \& A.H. Odhisa, India for providing necessary financial and administrative facilities to undertake the study.

\section{Competing interests}

The authors declare that they have no competing interests.

\section{References}

1. Taylor, M.A., Coop, R.L. and Wall, R.L. (2007) Veterinary Parasitology. 3rd Ed. Blackwell Publishing ltd, Oxford, UK, London.

2. Jadhav, R.K., Kumari, R.R., Jameel, A.J. and Kumar, P. (2011) Emergence of arthropod transmitted infections in kennel dogs. Vet. World. 4(11): 522-528.

3. Abd Rani, P.A.M., Irwin, P.J., Coleman, G.T., Gatne, M. and Traub, R.J. (2011) A survey of canine tick-borne diseases in India. Parasites \& Vectors. 4:141-148.

4. Agbolade, O.M., Soetan, E.O., Awesu, A., Ojo, J.A., Somoye, O.J. and Raufu, S.T. (2008) Ectoparasites of domestic dogs in some Ijebu communities, Southwest Nigeria. World Applied Sciences Journal. 3(6):916-920.

5. Troyo, A., Calderon-Arguedas, O., Alvarado, G., VargasCastro, L.E. and Avendano, A. (2009) Ectoparasite infestation on rural dogs in the municipality of Sao Vicente Ferrer, Pernambuco, Northeastern Brazil. Rev Bras Parasitol Vet., 18(3):75-77.

6. Jafri, S.A. and Rabbani, M. (1999) Prevalence of canine diseases in Lahore area. Pak. Vet. J. 19(1):40-42.

7. Misra, S.C. and Mohapatra, G.S. (1972) Prevalence of arthropod parasites of cattle, buffaloes, and dogs in Orissa. O.U.A.T. J.Res. 1:168-172. 
8. Raut, P.A., Maske, D.K., Jayraw, A.K. and Sonkusale, V.G. (2006) Ectoparasitism in dogs from the eastern zone of Maharashtra state. J. of Parasitic Dis., 30(2):138-141.

9. Ewing, S.A. (1969) Canine ehrlichiosis. Advances in Veterinary Science and Comparative Medicine 13: 331-353.

10. Ekanem, M. S., Mbagwu, H. O. C., Opara, K. N. and Agbata, Q. C. (2010) Ticks infestation of domestic dogs (Canisfamiliaris lupus) in UYO, AkwaIbom state, Nigeria. World Journal of Applied Science and Technology. 2(2):191-196.

11. James-Rugu, N.N. and Jidayi, S. (2004) A survey on ectoparasites of some livestock from some areas of Borno and Yobo States. Nigerian Vet. J., 25(2):48-55.

12. O'Dwyer, L.H., Massard, C.L., Pereira de Souza, J.C. (2001) Hepatozoon canis infection associated with dog ticks of rural areas of Rio de Janeiro State, Brazil. Vet Parasitol., 94 (3): 143-150.

13. Porchet, M.J., Sager, H., Muggli , L., Oppliger ,A., Müller, N. and Frey, C. (2007) A descriptive epidemiological study on canine babesiosis in the Lake Geneva region. Schweiz Arch Tierheilkd. 149(10):457-465.

14. Wells, K., Beaucournu, J.C., Durden, L.A., Petney, T.N., Lakim, M.B., O'Hara, R.B. (2012) Ectoparasite infestation patterns of domestic dogs in suburban and rural areas in Borneo. Parasitol. Res., 111(2):909-919.

15. Soundararajan, C., Anil Kumar, R. and Iyue, M. (2000) Otobius megnini infestation in dogs in Nilgiri. J. Vet. Parasitol. 14(1):87.

16. Martins, J.R., Evans, D.E., Cereser, V.H. and Correa, B.L. (2002) Partial strategic tick control within a herd of European breed cattle in the state of Rio Grande do Sul, southern Brazil. Experimental and Applied Acarology, 27: 241-251.

17. Jonsson, N.N., Matschoss, A.L., Pepper, P., Green, P.E., Albrecht, M.S., Hungerford, J. and Ansell, J. (2000a) Evaluation of TickGARDPLUS, a novel vaccine against Boophilus microplus in lactating Holstein-Friesian cows. Veterinary Parasitology, 88: 275-285.

18. Soulsby, E.J.L. (1982) Helminth, Arthropod and Protozoa of Domesticated Animals. $7^{\text {th }}$ Ed. Bailliere, Tindall and Cassel Ltd, London.

19. Snedecor, G.W. and Cochran, W.G. (1994) Statistical Methods. $6^{\text {th }}$ Ed. Oxford and IBH Publishing Co., New Delhi.

20. Singh, A. and Chhabra, R.C. (1973) Incidence of arthropod pests of domesticated animals and birds. Indian J. Ani. Sci.,43:393-397.
21. Moghaddar, S., Shorigeh, J. and Gastrodashty, A.R. (2001) Prevalence of ectoparasites and its seasonal prevalency in dogs in Shiraz (Iran). XII National Congress of Veterinary Parasitology, Abstr., S-2, 32, pp. 62.

22. Silveira, J.A., Passos, L.M. and Ribeiro, M.F. (2009) Population dynamics of Rhipicephalus sanguineus (Latrielle, 1806) in Belo Horizonte, Minas Gerais state, Brazil. Veterinary Parasitology, 161:270-275.

23. Arong, G. A., Shitta, K. B., James-Rugu, N. N. and Effanga, E. O. (2011) Seasonal variation in the abundance and distribution of ixodid ticks on Mongrel, Alsatian and mixed breeds of dogs (Canis familiaris) In Jos, In Plateau State, North-Central Nigeria. World Journal of Science and Technology. 1(4): 24-29.

24. Agbo, O.E., Ortwe, A.B. and Gbushum, A.J. (2007) Epidemiological survey of canine babesiosis in Makurdi, Nigeria. Animal Research International. 4(3):745-749.

25. Jittapalapong, S., Rungphisutthipongse, O., Maruyama, O.J., Schaefer, O. and Stich, R.W. (2006) Detection of Hepatozoon canis in stray dogs and cats in Bangkok, Thailand. Impact Em. Zoon. Dis. Ani. Health. 1081(8):479 488.

26. Dantas-Torres, F., Melo, M.F., Figueredo, L.A. and Brandao-Filho, S.P. (2009) Ectoparasite infestation on rural dogs in the municipality of Sao Vicente Ferrer, Pernambuco, Northeastern Brazil. Rev Bras Parasitol Vet. 18(3):75-77.

27. Ul-Hasan, M., Abubakar, M., Muhammad, G., Khan, M.N. and Hussain, M. (2012) Prevalence of tick infestation (Rhipicephalus sanguineus and Hyalomma anatolicum anatolicum) in dogs in Punjab, Pakistan. Vet Ital. 48(1):9598.

28. Dantas-torres, F. (2008) The brown dog tick, Rhipicephalus sanguineus (Latreille, 1806) (Acari:Ixodidae): from taxonomy to control. Vet. Parasitol., 152(3-4):173-185.

29. Kaul, H.N., Dhanda, V. and Mishra, A.C. (1979). A survey of ixodid ticks in Orissa state, India. Indian J. Ani., Sci., 1:5355.

30. Foldvari, G. and Farkas, R. (2005) Ixodid tick species attaching to dogs in Hungary. Veterinary Parasitology. 129 (2005):125-131.

31. Smith, F.D., Ballantyne, R., Morgan, E.R. and Wall, R. (2011) Prevalence, distribution and risk associated with tick infestation of dogs in Great Britain. Medical and Veterinary Entomology. 25(4):377-384. 